age: 49 y), medication and coexistence of other diseases influencing BMD were excluded.

The control group consisted of healthy reference persons, matched to persons in the DMO group.

BMD values were determined by DEXA measurements on the lumbal spine (L2-4) and on the femoral neck, employing a Norland XR-26 densitometer, with an excellent coefficient of reproducibility $(0.77 \%)$ over the $1.5 \mathrm{y}$ of the investigations.

Data significance was established by the t-probe analysis.

Results BMD values referring to L2-4 were significantly lower for the DMO $\left(0.86 \pm 0.15 \mathrm{~g} / \mathrm{cm}^{2}\right)$ as for the control group $\left(1.02 \pm 0.16 \mathrm{~g} / \mathrm{cm}^{2}\right)$, whereas BMD results for the femoral neck were $\left(0.76 \pm 0.11 \mathrm{~g} / \mathrm{cm}^{2}\right)$ and $\left(0.90 \pm 0.14 \mathrm{~g} / \mathrm{cm}^{2}\right)$, respectively. The difference of the BMD values for L2-4 was about 20\%, whereas for the femoral neck it amounted to $21 \%$. There is an indication that the peak BMD values for the DMO groupremain lower than those for the control group.

Conclusion These findings point strongly to the role of inheritance in the epigenesis of osteoporosis.

It is concluded that for individuals with increased genetic risk of osteoporosis an appropriate strategy, combining increased calcium uptake with an educated application of physical exercise, should be worked out.

Such a complex treatment could also increase the BMD values before menopause.

\section{AB0179 BONE MINERAL DENSITY MEASUREMENTS IN OBESE PATIENTS}

A Atalay, S Arslan, R Çeliker. Department of Physical Medicine and Rehabilitation, Hacettepe University, School of Medicine, Ankara, Turkey

\subsection{6/annrheumdis-2001.618}

Background Obese patients are prone to develop many medical conditions, including musculoskeletal problems. Obesity seems to have a protective effect on bone explained by metabolic mechanisms. Further studies will lead to better understanding of the impact of the weight on bone mineral density (BMD) measurements.

Objectives The aim of this study was to evaluate the relationship between obesity and lumbar and femoral BMD measurements.

Methods The study population consisted of 71 female patients from our outpatient clinics. Clinical assessment and anthropometric measurements (height, weight, abdominal circumference, waist circumference, triceps skinfold thickness) were performed by the same physician. Body mass index (BMI) was calculated as $\mathrm{kg} / \mathrm{m}^{2}$ and cut-off points defined by World Health Organisation (WHO) were used to identify obesity. Cut-off values are as follows: 18.5-24.99: normal, 25.0-29.99 grade1 overweight, 30.039.99 grade 2 overweight, $>=40.0$ grade 3 overweight. Lumbar and femoral BMD measurements were obtained using dual energy X-ray absorptiometry (DEXA) (Hologic QDR 4500A). Subjects were divided into two groups: subjects with BMI $<=$ 29.9 and subjects $>29.9$, and statistical analysis were carried out accordingly. $\mathrm{p}<0.05$ was considered to be statistically significant.

Results The mean age of the subjects was $52.96 \pm 10.87$ years (range: $25-78$ years) and mean BMI was $31.40 \pm 5.62$ (range: 21.91-47.27). According to WHO criteria: 12 subjects (16.9\%) were within the normal range, 16 subjects $(22.5 \%)$ were grade 1 obese, 39 subjects $(54.9 \%)$ grade 2 obese and 4 subjects $(5.6 \%)$ grade 3 obese. BMD measurements in all areas examined (lumbar total, L1, L2, L3, L4, intertrochanteric, neck, trochanteric and femoral total) were correlated with anthropometric measurements. BMI was positively correlated with lumbar and femoral bone mineral density measurements in all regions evaluated. BMD measurements in all areas examined (lumbar total, L1, L2, L3, L4, intertrochanteric, neck, trochanteric and femoral total) were compared according to two groups (BMI $<=29.9$, BMI > 29.9). In all areas there was a significant difference between the two groups in favour of the obese group.

Conclusion In accordance with the previous studies, our study indicates the positive relationship between obesity and bone mineral density measurements.

\section{REFERENCE}

1 World Health Organization. Physical status: The use and interpretation of anthropometry. Report of a WHO expert committee. Geneva: World Health Organization, 1995

\section{AB0180 FOLLOW UP STUDY TO DETERMINATE THE ACHIEVEMENT OF THE PEAK BONE MASS AT 18-25 YEARS OLD YOUNG PEOPLE}

G László. Rheumatology, Central Hospital of Hungarian Army, Budapest, Hungary

\subsection{6/annrheumdis-2001.619}

Background The aim of our study was to follow up and determinate the achievement of the bone mass in young age. We wanted to study, what can influence the growth of the bone mass.

Objectives We began our study 3 years ago. We made examinations among 18 years old young men and women, who begun the first class in two military academies just then. The physical education is an important part of the programme of the military academies, that?s why these groups are ideal to establish the statement, that the sport results the increasing of the bone mass in this age. We organised a control group too, in a civil university, where sporting not obligatory. The participation was voluntary.

Methods Every participant filled a questionnaire about his/her earlier diseases, good and bad habits (e.g.: sport, smoking), and about his/her alimentary habits (e.g. milk and dairy products). We measured the bone density in their arms and ankle. We made anthropometrical and staying power examinations too. Finally we made laboratory tests to determinate the elements of the calcium household. The examinations were repeated two times.

Results We found, that according to the osteodensitometry the bone mass have grown in all of the groups. At the soldier men's group the increase was more significant, than at the others. The degree of bone mass growth connected with the body mass index, exactly with the growing of the body weight. According to the anthropometrical examinations the growth of the body weight came rather from the growth of the muscle mass than bone mass. Though the bone density grew, its weight did not grow significantly.

Conclusion It seems that, neither the nutrition, nor the bad habits cannot influence the bone mass significantly in this young age. But the moving, sporting play important roles in the achievement of the peak bone mass. 


\section{AB0181 EPIDEMIOLOGY STUDY ABOUT OSTEOPOROSIS IN POSTMENOPAUSAL WOMEN ABOUT 1000 CASE}

S Quennesson, E Quennesson, PM Preux, C Scotto Di Fazano, D Coyral, P Vergne, C Bonnet, P Bertin, R Treves. Rheumatology, Universitary Hospital Limoges, Tauxigny, France

\subsection{6/annrheumdis-2001.620}

Background Osteoporosis is a bone disease who concerns above all postmenopausal women. It's characterised by bone loss and associated fractures. In France, in 1995 it's 1\% hospital cost. We realised a transversal study about osteoporosis and risk factors with 1000 women.

Objectives We excluded women with hormonal substitutive treatment and secondary osteoporosis. The study group was randomised. All patients were interviewed about risk factor and bone mineral density was measured by dual energy $\mathrm{X}$ ray. One woman was excluded for myeloma.

Methods We compared risk factor between osteoporosis group and non osteoporosis group determined by densitometry OMS criteria, with student $t$ test or chi2. Finally a multivarious analysis includes all significative risk factor. $(\mathrm{p}<0,05)$.

Results In our study, there was $25 \%$ osteoporotic patients. The univarious analysis find a significant relation between osteoporosis and study level, the age at menopause, thyroid disease, body mass index, calcium intake, milk drink, fresh water consumption, white cheese. The multivarious analysis shows a significant relation between osteoporosis and age (odds ratio $=1,1$ per year), the level study (odds ratio $=0,34$ between; after first grade diploma and no education), Body Mass Index (odds ratio $=$ 0,86 per unity), milk drinks (odds ratio $=0,7$ ).

The discriminant analysis after further adjustment for confounding factors allows to diagnose $67 \%$ of osteoporotic women.

Conclusion In our population, we find some usual risk factor of literature.

The interview is not sufficient to diagnose osteoporosis certainly but allow to purpose bone density. The results of this bone density with clinical information is necessary to start the best treatment.

\section{AB0182 HIP VS CALCANEUS BONE MINERAL DENSITY IN POSTMENOPAUSAL WOMEN}

JA Román-Ivorra, L Abad, C Fernández-Carballido, JJ Alegre-Sancho. Rheumatology, Hospital Universitario Dr. Peset, Valencia, Spain

\subsection{6/annrheumdis-2001.621}

Background Assessment of postmenopausal osteoporosis is usually delayed due to central densitometers' lack in some areas. Peripheral densitometers have been proposed for osteoporosis screening.

Objectives To assess the relationship between bone mineral density (BMD) measurements in post-menopausal women using central (DEXA) and peripheral (PIXI) densitometers.

Methods 81 women, included in a post-menopausal osteoporosis assessment schedule, were consecutively selected for this study. In all women, we collected: 1) an osteoporosis risk factors' questionnaire; 2) measurement of hip BMD, using a DEXA densitometer (NORLAND); and 3) measurement of calcaneus BMD, using the peripheral densitometer PIXI(LUNAR).

Results Osteoporosis risk factors collected: mean age (years) = 63(9.6 sd); mean time since menopause (years) $=15.6(9.2 \mathrm{sd})$; mean body mass index $=28.9(4.5 \mathrm{sd})$; mother's hip fracture $=$ $6.2 \%$; previous Colles fracture $=8.6 \%$; previous vertebral fracture $=6.2 \%$; previous hip fracture $=1.2 \%$; other non-traumatic fractures $=13.6 \%$; calcium intake $<1 \mathrm{~g} / \mathrm{d}=88.9 \%$; sedentarism $=45.7 \%$. Statistical significance was found between absolute BMD values (Pearson's correlation coefficient: $\mathrm{r}=0.501(\mathrm{p}=$ $0.01)$ ), and t-score values (Pearson's correlation coefficient: $\mathrm{r}=$ $0.575(\mathrm{p}=0.01))$ obtained with both densitometers.

Conclusion Peripheral densitometers can be a reliable and suitable choice for postmenopausal osteoporosis screening in primary health centres.

\section{AB0183 CORRELATION BETWEEN THE BONE MINERAL DENSITY AND THE OBESITY IN HEALTHY WOMAN}

NZ Vujasinovic-Stupar, P Vukojevic, NZ Pilipovic. Clinical Department I, Institute of Rheumatology-Belgrade, Belgrade, Yugoslavia

10.1136/annrheumdis-2001.622

\section{Background}

Objectives

Methods In 425 randomly chosen women, bone mineral density (BMD) assessment of lumbar spine (region L2-L4) was done using LUNAR DPXL device. All the subjects included were healthy with negative significant risk factors for osteoporosis. The demographic data of included subjects are: Mean age of women was 47.1 (20-78) yrs; menarche mean age was 13.5 (10-19) yrs; average weight $68.8(45-107) \mathrm{kg}$ and average height $160(147-183) \mathrm{cm}$; mean value of BMI was $25.6(14.8-$ $45.6) \mathrm{kg} / \mathrm{m}^{2}$; mean value of BMD was $1.16(0.701-1.98) \mathrm{g} / \mathrm{ccm}$.

According to BMI the subjects were divided in 4 groups (grade $0=$ normal, grade $1=$ mild obesity, grade $2=$ moderate obesity and $3=$ severe obesity) and the linear correlation test was done between BMD and BMI.

Results The results with correlation coefficient $(\mathrm{R})$ and corresponding $\mathrm{p}$ values are shown in the Table 1 .

\begin{tabular}{llllll}
\multicolumn{5}{l}{ Abstract AB0183 Table 1} & \multicolumn{1}{l}{ Correlation between BMI and BMD } \\
\hline \multicolumn{7}{c}{ BMI $\left(\mathbf{k g} / \mathbf{m}^{2}\right)$} \\
\hline Group $/ \mathbf{N}$ & $0 / 234$ & $1 / 104$ & $11 / 69$ & $111 / 18$ & Total/425 \\
BMD $\left(\mathbf{g} / \mathrm{cm}^{2}\right)$ & $22.4 \pm 1.9$ & $27.0 \pm 1.4$ & $31.3 \pm 1.6$ & $37.3 \pm 1.93$ & $25.6 \pm 4.6$ \\
$\mathbf{R}$ & 0.078 & 0.233 & 0.27 & -0.497 & 0.134 \\
$\mathbf{p}$ & 0.906 & 0.16 & 0.021 & 0.036 & 0.006 \\
\hline
\end{tabular}

Conclusion The significant positive correlation $(p=0,006)$ was observed between lumbar spine BMD and BMI in whole group. In subjects with normal BMI (group 0) and mild obesity such correlation was not present. In subjects with moderate obesity significant positive correlation was observed $(p=0,021)$, while in group representing severe obesity subjects highly significant negative correlation was calculated $(\mathrm{p}=0,036)$.

\section{AB0184 MISDIAGNOSIS OF INSUFFICIENCY FRACTURES IN PATIENTS WITH INFLAMMATORY JOINT DISEASE}

${ }^{1} \mathrm{D}$ Schapira, ${ }^{2} \mathrm{D}$ Militianu, ${ }^{1} \mathrm{Y}$ Braun-Moscovici, ${ }^{1} \mathrm{AM}$ Nahir. ${ }^{1}$ Rheumatology Service;

${ }^{2}$ Department of Diagnostic Radiology, Rambam Medical Center, Haifa, Israel

10.1136/annrheumdis-2001.623 